\title{
Unique and Interactive Effects of Moral Emotions and Moral Disengagement on Bullying and Defending among School Children
}

\author{
Robert Thornberg, Tiziana Pozzoli, Gini Gianluca and Tomas Jungert
}

\section{Linköping University Post Print}

\section{Tweet}

N.B.: When citing this work, cite the original article.

Original Publication:

Robert Thornberg, Tiziana Pozzoli, Gini Gianluca and Tomas Jungert, Unique and Interactive Effects of Moral Emotions and Moral Disengagement on Bullying and Defending among School Children, 2015, The Elementary school journal, (116), 2, 322-337.

http://dx.doi.org/10.1086/683985

Copyright: University of Chicago Press

http://www.press.uchicago.edu/

Postprint available at: Linköping University Electronic Press

http://urn.kb.se/resolve?urn=urn:nbn:se:liu:diva-123595 


\title{
UNIQUE AND INTERACTIVE EFFECTS OF MORAL EMOTIONS AND MORAL DISENGAGEMENT ON BULLYING AND DEFENDING AMONG SCHOOL CHILDREN
}

\begin{abstract}
A B S T RACT
The first aim of the present study was to examine in a single model how moral disengagement and moral emotions were related to bullying and defending behavior among schoolchildren. The second aim was to test whether the two moral dimensions interacted with each other to explain behavior in bullying situations. Data were collected from 561 Swedish students. Moral disengagement was positively associated with bullying and negatively associated with defending, whereas moral emotions score was negatively associated with bullying and positively associated with defending. Moreover, students who scored high in moral emotions did not tend to bully other students, irrespective of their levels of moral disengagement, whereas when the moral emotions score was low bullying behavior increased with increasing levels of moral disengagement. In contrast, moral disengagement was negatively related to defending behavior at low levels of moral emotions, but not when moral emotions were high.
\end{abstract}

Robert Thornberg

LINKÖPING UNIVERSITY

Tiziana Pozzoli

Gianluca Gini

UNIVERSITY OF PADOVA

Tomas Jungert

LINKÖPING UNIVERSITY

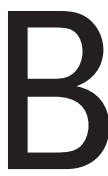

U L LY IN G is an immoral action due to its repeated harmful intentions and negative effects on a person in a weaker position (Bauman, 2008; Hymel, Schonert-Reichl, Bonanno, Vaillancourt, \& Rocke Henderson, 2010). Smith and Sharp (1994) define bullying as "systematic abuse of power" (p. 2). In contrast, defending a victim in bullying situations can be considered a moral action because it aims at protecting the welfare and rights of the victim. It is an example of

THE ELEMENTARY SCHOOL JOURNAL VOLUME 116 , NUMBER 2

(C) 2015 by The University of Chicago. All rights reserved. 0013-5984/2015/11602-0007 $\$ 10.00$ 
humane, caring, and prosocial behavior. Hence, bullying and defending have opposite intrinsic effects on the well-being of the victim. Whereas refraining from bullying others is an inhibitive form of morality, defending a victim is a proactive form of morality (see Tisak, Tisak, \& Goldstein, 2006).

Research on morality has devoted considerable attention to processes that explain the association between moral cognitions and actual moral or immoral actions. Classic cognitive-developmental theories of moral development (Kohlberg, 1976, 1984; Piaget, 1932) maintain that moral reasoning develops with age across a set of invariant stages, and that actual actions are the logical consequence of moral reasoning and knowing the correct behavior in a given situation. However, these cognitive constructivist theories also agree in assuming that moral development is not an obligatory process, and a moral delay can happen, thus increasing the risk of antisociality (Emler \& Tarry, 2007; Gibbs, 2010). Yet studies on peer bullying have found that bullying behavior is not necessarily related to lack of cognitive skills in moral reasoning (e.g., Caravita, Miragoli, \& Di Blasio, 2009; Gasser \& Keller, 2009; Gini, Pozzoli, \& Hauser, 2011). More relevant areas of inquiry deal with moral emotions and specific distortions in moral cognition, such as moral disengagement mechanisms (Gini, Pozzoli, \& Hymel, 2014; Malti \& Krettenauer, 2013).

\section{Moral Emotions}

In general, children consider bullying to be highly immoral (Menesini et al., 1997; Thornberg, 2010; Thornberg, Birberg Thornberg, Alamaa, \& Daud, in press), wrong independently of rules, more wrong than conventional transgressions, and justify their bullying judgments by referring to the harm bullying causes (Thornberg, 2010; Thornberg et al., in press). However, Bandura (1999) suggested that moral knowledge or reasoning is not enough but has to be translated into moral conduct through self-regulatory mechanisms rooted in moral standards and self-sanctions. Moral emotions have been suggested as a significant source of motivation for moral conduct (e.g., Eisenberg, 2000; Haidt, 2003; Hoffman, 2000). With reference to Haidt (2003), moral emotions are the emotions that respond to moral violations and motivate moral behavior. They are associated with the help/harm dimension of behavior and the dyadic positions in the help/harm situation - an agent position, that is, the one who assaults or rescues, and a patient position, that is, the one to be assaulted or rescued (Gray \& Wegner, 2011).

In the literature, three often-discussed moral emotions are empathy, sympathy, and guilt (Bierhoff, 2002; Eisenberg, 2000; Hoffman, 2000). The positive association between empathy and prosocial behavior has been found in several studies (for reviews, see Eisenberg, Eggum, \& Di Giunta, 2010; Eisenberg, Spinrad, \& Sadovsky, 2006; Hoffman, 2000). In the context of bullying, students with a high level of empathy are more likely to take the defender role (Barchia \& Bussey, 2011b; Caravita, Di Blasio, \& Salmivalli, 2009, 2010; Correia \& Dalbert, 2008; Gini, Albiero, Benelli, \& Altoè, 2007), whereas students with a low level of empathy are more likely to take the bully role (Correia \& Dalbert, 2008; Jolliffe \& Farrington, 2006; Stavrinides, Georgiou, \& Theofanous, 2010) or display pro-bullying behavior (Gini et al., 2007). Like empathy, sympathy also has been found to be positively associated with prosocial behavior (for reviews, see Eisenberg et al., 2006, 2010; Hoffman, 2000) and negatively associated with aggression (Carlo et al., 2010; MacEvoy \& Leff, 2012). Furthermore, 
previous research with children and adolescents has shown that guilt is negatively related to aggression (Roos, Salmivalli, \& Hodges, 2011), bullying (Menesini et al., 2003; Perren \& Gutzwiller-Helfenfinger, 2012; Perren, Gutzwiller-Helfenfinger, Malti, \& Hymel, 2012), and antisocial behavior (Lotze, Ravindran, \& Myers, 2010) and positively associated with empathy (Hoffman, 2000; Silfver \& Helkama, 2007) and prosocial behavior (Olthof, 2012). Hence, it is reasonable to assume that moral emotions as an index of empathy, sympathy, and guilt have an impact on students' behavior in bullying situations.

\section{Moral Disengagement}

Empathic distress and other moral emotions may be reduced or even neutralized as a result of attributions and other processes (Hoffman, 2000). As outlined in the social-cognitive theory of moral agency (Bandura, 1999), there are many social and psychological maneuvers by which self-regulated mechanisms can be deactivated and moral self-sanctions can be disengaged from immoral conduct. Moral disengagement refers to such sociocognitive processes through which people can disengage from moral control and thus commit inhumane acts toward other people without suffering negative self-sanctions. Specifically, Bandura (1999) described eight mechanisms, clustered into four broad categories through which moral control can be disengaged: (1) cognitive restructuring (e.g., "Stealing is not really harmful when compared with murder"); (2) minimizing one's agentive role (e.g., "I was not the only one to have such behavior"); (3) minimizing, disregarding, or distorting the consequences (e.g., "I didn't really hurt him. He's OK”); (4) dehumanizing or blaming the victim (e.g., "He is an animal and deserves what I did").

Almost 2 decades of research have shown that moral disengagement is positively associated with aggressive behavior (Bandura, Barbaranelli, Caprara, \& Pastorelli, 1996; Bandura, Caprara, Barbaranelli, \& Pastorelli, 2001; Barchia \& Bussey, 2011a; Paciello et al., 2008; Pelton et al., 2004; Pornari \& Wood, 2010; for a meta-analysis, see Gini et al., 2014) and negatively associated with prosocial behavior (Bandura et al., 1996, 2001). In the context of bullying, students with higher levels of moral disengagement are more likely to take the bullying role (Caravita, Gini, \& Pozzoli, 2012; Gini, 2006; Gini et al., 2011; Hymel, Rocke-Henderson, \& Bonanno, 2005; Obermann, 2011a; Perren \& Gutzwiller-Helfenfinger, 2012; Perren et al., 2012; Thornberg \& Jungert, 2014) or pro-bullying roles (Gini, 2006; Pozzoli, Gini, \& Vieno, 2012; Thornberg \& Jungert, 2013) and less likely to take the defender role (Caravita et al., 2012; Gini, 2006; Obermann, 2011b; Thornberg \& Jungert, 2013).

\section{Present Study}

One possible limitation of the current literature on this issue is that studies so far have usually assessed independently the role of moral disengagement or moral emotions in bullying behavior and, to a lesser extent, defending the victim. What is currently unknown is whether their role is confirmed when they are concurrently considered as potential predictors of bullying and defending behavior. Moreover, instead of assessing emotion attribution in hypothetical scenarios, which are common in previous studies on moral emotions (Malti \& Krettenauer, 2013), it would be important to ask students how they feel when they participate in or witness bullying. 
The first aim of the present study was to examine in a single model how moral disengagement and moral emotions were related to bullying and defending behavior among schoolchildren. That is, we were interested in studying the role of each moral dimension (i.e., their main effect) while taking into account the role of the other one on both behaviors. We hypothesized that both moral dimensions would contribute significantly to explaining the variance of both bullying others and defending the victim. If true, this would indicate that, although correlated, moral emotions and moral disengagement are uniquely associated with bullying and defending behavior and are worth studying together.

The second aim was to test whether the two moral dimensions interacted with each other to explain behavior in bullying situations (i.e., moderation effects). According to Bandura (1999), moral disengagement is produced by the reciprocal interplay of cognitive, affective, and social factors. It is therefore reasonable to assume an interaction effect between affective and cognitive dimensions of morality in relation to bullying and defending behavior. Previous studies have found the link between moral disengagement and different moral emotions. For example, moral disengagement has been negatively associated with empathy (Almeida, Correia, \& Marinho, 2010; Barriga, Sullivan-Cosetti, \& Gibbs, 2009; Hyde et al., 2010) and feelings of guilt regarding moral transgressions (Bandura et al., 1996; Perren \& Gutzwiller-Helfenfinger, 2012). In Obermann's (2011b) study, so-called “unconcerned passive bystanders" displayed a higher level of moral disengagement compared with defenders and "guilty passive bystanders." By integrating the concept of moral emotions (i.e., empathy, sympathy, and moral guilt) with Bandura's socialcognitive theory of moral agency and moral disengagement, we claim that adolescents who are more prone to feel moral emotions in bystander or transgressor encounters (see Hoffman, 2000) are more resistant to moral disengagement. Moral emotions are associated with the construction of moral-action schemas and have been integrated within the overall conceptual framework guiding the child's morality (Hoffman, 2000; Nucci, 2001). Thus, because aroused moral emotions should make internalized moral standards or moral-actions schemes more easily accessible and persistent in exerting a pervasive interpretative influence over social information processing in bystander and transgressor encounters, aroused moral emotions should make it harder for moral disengagement mechanisms to influence actions. Therefore, we hypothesized moderation effects of moral emotions on the relation between moral disengagement and both bullying and defending: High levels of moral emotions should weaken the positive link between moral disengagement and bullying as well as weakening the negative link between moral disengagement and defending.

\section{Method}

\section{Participants and Procedure}

Participants were recruited from 28 elementary school classes (fifth and sixth grades) from 11 public schools located in two cities and two villages in Sweden. The Swedish school system consists of a kindergarten year (the year children become 6 years old) and then 9 years of compulsory schooling including elementary school (grades 1-6) and secondary school (grades 7-9). In elementary school, students have 
a home classroom in which they have most of their classes, and they have the same class teacher for most school subjects. Their class teacher follows them through grades $1-3$, and then a new class teacher follows them through grades $4-6$. In secondary school, students meet a variety of subject teachers and they change classrooms for each class.

The original sample consisted of 615 (56.5\% boys) students. School principals and teachers were asked first for consent. Parental consent letters were then distributed to all the families. Finally, all the participants were asked for their consent. The final sample consisted of 561 students $\left(50.6 \%\right.$ boys; $M_{\text {age }}=11$ years, 8 months, $S D=6$ months), resulting in a participation rate of $91.2 \%$. Socioeconomic and ethnic background data were not gathered on an individual level. Nevertheless, the sample was recruited from schools located in neighborhoods of different socioeconomic statuses, representing both the lower and middle classes. Based on information from the schools, the large majority of the participants have a Swedish ethnic background.

The participants filled out a questionnaire in their ordinary classroom setting. Three student teachers, at the end of their teacher training, were present in the classrooms during the data gathering (one student teacher in each classroom). They explained the study procedure, assured confidentiality, and assisted the participants who needed help. The participants responded anonymously to the questionnaire.

\section{Measures}

Bullying behavior. A six-item Swedish bullying scale (Thornberg \& Jungert, 2014) was used to measure participants' bullying behavior. The participants were asked, "How often have you alone or together with others done the following things at school toward the same person in the past three months?" Two items measured physical bullying: "Beat or kicked the person in order to give him/her pain" and "Shoved or held the person against his/her will." Two items measured verbal bullying: "Teased and called the person mean names" and "Made fun of or joked about the person in a way he/she didn't like.” Two items measured relational bullying: "Excluded the person from our group" and "Spread mean rumors or lies about the person." The participants indicated how often they behaved as described in each item on a five-point scale ( $0=$ "I haven't done that," $1=$ "a couple of times," $2=$ " 2 or 3 times a month," $3=$ "about once a week," $4=$ "several times a week"). The scores of the scales measuring the three types of bullying were strongly correlated $(.66<r<$ $.71)$; thus answers to the six items were averaged to form a single bullying score (Cronbach's $\alpha=.88$ ).

Defending behavior. A shortened version of Thornberg and Jungert's (2014) defending scale was used to measure participants' defending behavior in aggression situations. This 10-item scale consisted of two sections. In the first section (witnessing physical aggression), the participants were asked, "When one or more students are beating, kicking, harshly shoving, or holding another student in order to make the person upset, what do you usually do?" In the second section (witnessing verbal aggression), the participants were asked, "When one or more students are teasing, threatening, or calling another student mean names in order to make the person upset, what do you usually do?" The same five items followed the question in each of the two sections: "I go and tell a teacher," "I try to make them stop," "I try to comfort the exposed student," "I try to defend the exposed student," and "I tell them to stop 
fighting with the student." The participants indicated how often they respond in accordance with the behavior described in each item (o = "never," $1=$ "seldom," $2=$ "sometimes," 3 = "usually," 4 = "always"). Given the high correlation between the scores of defending during verbal and physical aggression $(r=.85)$, answers to the 10 items were averaged to form a single score of defending (Cronbach's $\alpha=.94$ ).

Moral emotions. A 12-item Moral Emotions Scale was designed to measure the degree of moral emotions with relevance for bullying situations. Four items tapped empathy with the victim ("I feel sad if I see a bullied person being sad," "It hurts me if I see a person being bullied," "I feel sad if I see someone being sad because others are teasing him or her," "If someone who is teased starts crying, it would feel like I would become upset too"). Two items tapped sympathy for the victim ("If I see someone being bullied, I would really feel sorry for that person," "If someone is sad because others are teasing him/her, I would really feel sorry for that person"). Three items tapped guilt for inaction, that is, guilt for not helping or defending the victim ("I feel like a bad person if I just stand and watch and do nothing when a person is bullied," "If I see someone being bullied and if I don't try to help that person, I would feel guilty," "If I don't try to stop bullying I'm seeing, I would feel guilty"). Three items tapped transgressive guilt, that is, guilt for bullying or harassing another person ("I would feel guilty if I tease a person," "I feel guilty if I bully another person," "I would feel like a bad person if I bully another person"). Participants rated each item on a seven-point scale, where 1 means "disagree" and 7 means "agree." Even though the items were designed to measure different moral emotions, the four categories of moral emotions were highly intercorrelated (correlations ranged from .72 to .85), and a factor analysis (principal components, Varimax rotation) yielded a single factor that did not distinguish the different moral emotions. Therefore, answers on all items were averaged to form a single score of moral emotions $(\alpha=.97)$.

Moral disengagement. An 18-item Swedish Moral Disengagement in Bullying Scale (MDBS; Thornberg \& Jungert, 2014) was used to measure participants' proneness to morally disengage in bullying situations. Examples of items are: "It's okay to hurt another person a couple of times a week if you do that to protect your friends," "There's nothing wrong with name-calling a person a bit every day as long as you just do it as a joke," "If my friends begin to bully a classmate, I can't be blamed for being with them and bullying that person too," and "If people are weird, it is their own fault if they get bullied." Participants rated each item on a seven-point scale, where 1 means "disagree" and 7 means "agree" (Cronbach's $\alpha=.90)$.

\section{Results}

\section{Descriptive Statistics and Correlations among Study Variables}

Descriptive statistics of the study variables are reported in Table 1. Gender differences in mean scores were tested through a series of $t$-tests, and effect sizes are expressed as Cohen's $d$. Boys scored higher than girls on bullying and moral disengagement, while girls reported greater defending behavior and moral emotions, which refers to an index of empathy, sympathy, and moral guilt, as compared with boys.

Correlations among variables were analyzed separately for boys and girls (see Table 1). In both groups, moral disengagement negatively correlated with moral 
Table 1. Descriptive Statistics and Correlations among the Study Variables

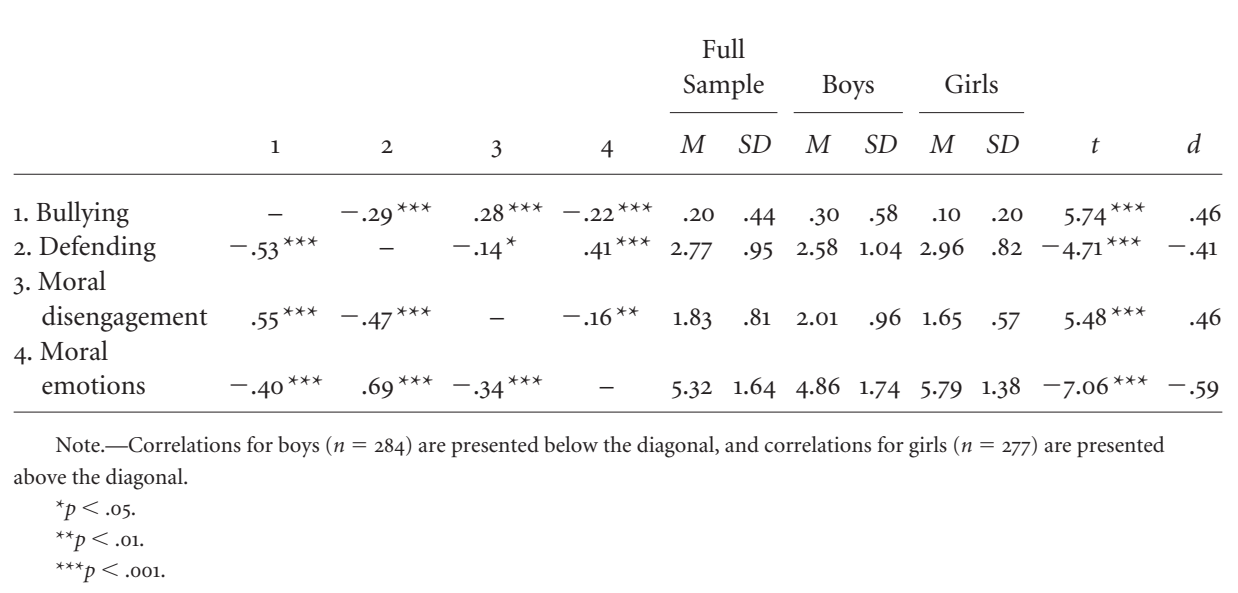

emotions. Moreover, it was positively related to bullying and negatively associated with defending behavior. The opposite pattern of results was observed concerning moral emotions. Finally, a negative association between bullying and defending behavior emerged. Overall, the magnitude of the correlation coefficients was greater for boys than for girls.

\section{Path Analysis}

Because the results of both the $t$-tests and correlation analysis showed some gender differences in the study variables, to control for gender effects the path model was tested on the partial correlation matrix, in which the effect of gender was partialed out, using the LISREL 8.7 Program (Jöreskog \& Sörbom, 1993). Bullying and defending scores were entered in the model as the observed dependent variables, whereas participants' scores for moral disengagement and moral emotions were entered as observed independent variables. Furthermore, to test for moderation, the procedure proposed by Baron and Kenny (1986; see also Frazier et al., 2004) was followed, so that independent variables were centered around their mean to create the interaction term. The interaction resulting from the product of the two mean-centered variables was entered in the model.

The final model is depicted in Figure 1 (all paths reached statistical significance). Given that the path model reproduced exactly the observed data, the indexes commonly used to evaluate the fit of the model cannot be calculated. The only available index is the amount of variance explained by the model $\left(R^{2}\right)$, which is .31 for bullying and .39 for defending behavior. The main effects of both moral disengagement and moral emotions on bullying and defending behavior (in opposite directions) were significant. Moreover, as hypothesized, the interaction term moral disengagement $\times$ moral emotions was significant.

As far as bullying behavior is concerned, results of follow-up analysis (Fig. 2) revealed that at high levels $\left(+{ }_{1} S D\right)$ of moral emotions, the relation between moral disengagement and bullying was very small $(\beta=.06, t=1.80, p=.07)$, so that students who scored high in moral emotions did not tend to bully other students, irrespective of their levels of moral disengagement. Conversely, when the moral 


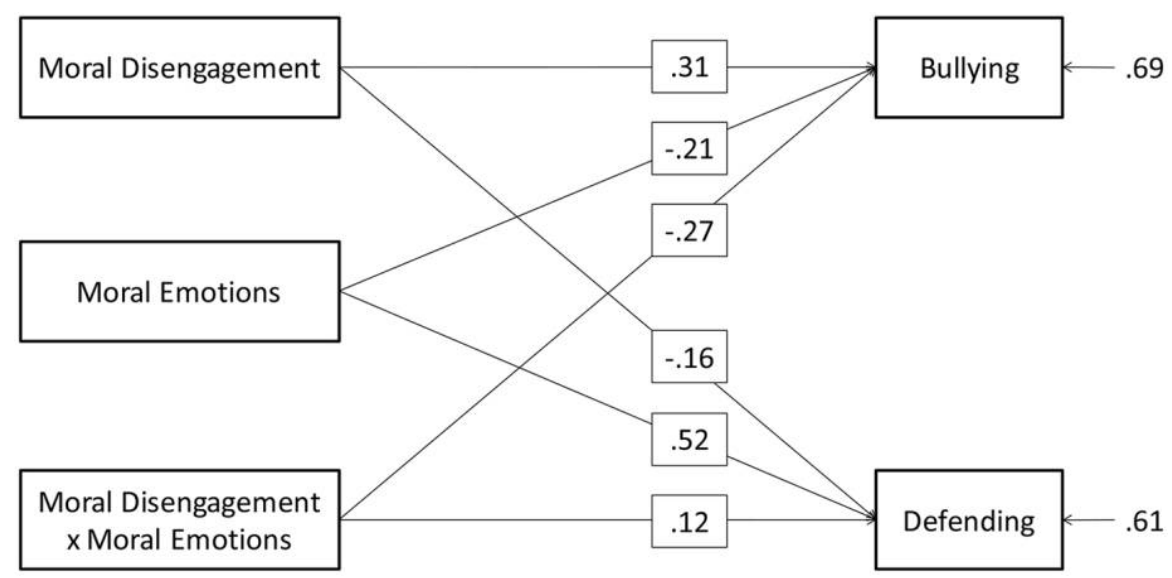

Figure 1. Final path graph.

emotions score was low $\left(-_{1} S D\right)$, bullying behavior increased with increasing levels of moral disengagement $(\beta=.28, t=13.67, p<.001)$. With regard to defending behavior, as one can see in Figure 2, moral disengagement was negatively and significantly related to defending at low levels of moral emotions $(\beta=-.29, t=-7.14, p<$ $.001)$, but not when moral emotions were high $(\beta=-.08, t=-1.17, p=.24)$. In the latter case, participants' level of defending behavior was high notwithstanding their proneness to morally disengage.

\section{Discussion}

Within the field of moral psychology and development, several scholars have recently stressed the importance of theoretically integrating moral cognition and moral emotions and empirically investigating both moral dimensions in order to explain individual differences in moral as well as immoral behavior (Arsenio \& Lemerise, 2004; Hoffman, 2000; Malti \& Latzko, 2010; Perren \& Gutzwiller-Helfenfinger, 2012). In line with this integrative perspective, this study was the first to examine in a single model how moral disengagement and moral emotions were related to bullying and defending behavior among schoolchildren. Specifically, we tested whether moral disengagement and moral emotions uniquely contributed to explain both behaviors and whether the two moral dimensions interacted with each other in explaining these behaviors in bullying situations.

Consistent with previous studies (e.g., Caravita et al., 2012; Gini, 2006; Gini et al., 2011; Perren et al., 2012; Thornberg \& Jungert, 2013), moral disengagement was positively associated with bullying behavior and negatively associated with defending behavior. As hypothesized, these associations remained when moral emotions were included in the same model. This finding adds to previous studies that have shown that the link between moral disengagement and aggressive behavior is significant even after the role of other variables, such as aggression efficacy, rule perception, or parenting, is accounted for (e.g., Barchia \& Bussey, 2011a; Caravita et al., 2012; Pelton et al., 2004). Furthermore, because empathy and guilt have been found to be negatively associated with bullying behavior and positively associated with defending behavior (e.g., Barchia \& Bussey, 2011b; Correia \& Dalbert, 2008; Menesini et al., 2003), we expected a similar pattern between the construct moral emotions, which 

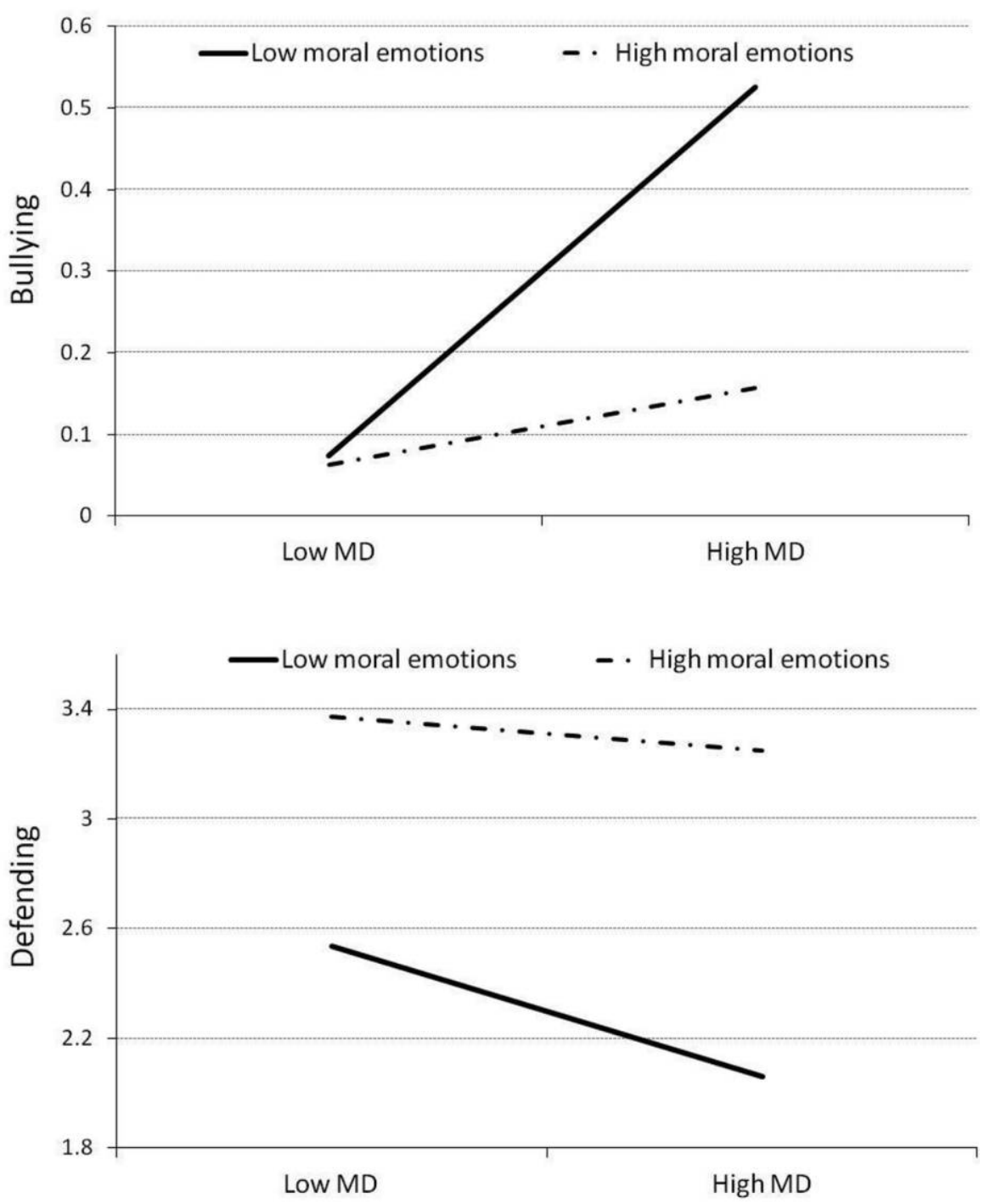

Figure 2. The moral disengagement $\times$ moral emotions effect on bullying and defending behavior.

here refers to a total index of empathy, sympathy, and moral guilt, and the two behaviors in bullying situations. The current findings confirmed that these relationships hold even when controlling for moral disengagement. Hence our study revealed that both moral emotions and moral disengagement are uniquely associated with both bullying and defending behavior.

Although these main effects confirm the relevant role of both moral dimensions in bullying, little is known about how moral disengagement interacts with other individual risk factors (Gini et al., 2014). The model tested in the present study showed that moral emotions moderated the effect of moral disengagement on both bullying and defending behavior. This is a new and interesting result because it suggests that bullying behavior is more likely with higher levels of moral disengagement among students who display low levels of moral emotions. Conversely, students who displayed high levels of moral emotions did not tend to bully others irrespective of their levels of moral disengagement. Moreover, defending behavior decreased with in- 
creasing levels of moral disengagement among students with a low level of moral emotions, but students who scored high in moral emotions also reported a high level of defending behavior irrespective of their levels of moral disengagement. Hence, our findings suggest that strong moral emotions tend to overrule moral disengagement associations with behavior in bullying situations, at least in this age group. In accordance with Hoffman (2000), moral emotions such as empathy, sympathy for the victim, and moral guilt do all display an individual's awareness of the harmful consequences for the victim. In the online processing of social information (see Arsenio \& Lemerise, 2004; Hoffman, 2000), "hot" cognitions evoked by moral emotions draw attention to the victim's distress and the moral issues in the situation in a way that seems to be more persuasive and forceful than any parallel presence of moral disengagement.

Overall, these results suggest that the construct moral emotions-not only in terms of moral sanctions that could be associated with guilt when violating moral standards (Bandura, 1999, 2004) but as a construct that covers empathy, sympathy for victims, transgressive guilt, and guilt for inaction (Hoffman, 2000)-may be crucial to incorporate with the social-cognitive theory of moral agency (Bandura, 1999, 2004) to better understand and explain bullying and defending behavior. This is actually congruent with the social-cognitive theory because it proposes that actions are the outcome of the reciprocal interplay of cognitive, affective, and social factors (Bandura, 1986, 1999, 2004). This is also consistent with other models that seek to explain the moral "inability" that lies under antisocial conduct, such as the "violence inhibition mechanism" (e.g., Blair, 2001). Briefly, this mechanism is activated by distress cues (e.g., the sad and frightened expressions of others), and moral socialization occurs through the pairing of the activation of the mechanism with representations of the acts that caused the distress cues (i.e., the moral transgressions). If the activation of this mechanism is partially inhibited, moral transgressions are enacted more easily. Furthermore, our results support Barhight, Hubbart, and Hyde (2013), who recently found that children who reacted with high negative emotions and heart rate acceleration when watching bullying videos in a laboratory setting were more prone to intervene in real-life bullying than children who reacted with low negative emotions and heart rate deceleration when watching these videos.

\section{Limitations and Implications for Interventions}

Limitations of this study include the self-report procedure, which is vulnerable to social desirability and shared method variance effects (Cornell \& Bandypadhyay, 2010). Furthermore, we used a cross-sectional design, and we therefore are not able to pinpoint the direction of effects between moral disengagement and emotions and bullying-related behaviors. Further studies would need to take a longitudinal approach to investigate the directions of the effects. Thus, identified associations as well as drawing causal conclusions based on the associations should be considered with great caution. In addition, the defending behavior scale assumes that the participants have witnessed physical and verbal aggression among their peers. In some cases, it might be possible that the response option "never" could have been misinterpreted as never having witnessing such aggression rather than never having intervened in the way described. However, the participants were in fact asked to rate what they usually did when one or more students acted in accordance with at least one of the 
described aggressive behaviors. According to a recent report from the Swedish National Agency for Education (2013), 12\% of the students in grades 4-6 reported that they are peer victimized at school on a weekly basis. To assume that students more than once have witnessed at least one example of physical aggression (beating, kicking, harshly shoving, or holding another student to make the person upset) and at least one example of verbal aggression (teasing, threatening, or calling another student mean names) mentioned in the scale is therefore reasonable. Finally, a note of caution needs to be sounded regarding the generalization of the findings. This sample of early adolescents from Sweden may or may not be similar to the population of adolescents with whom the readers primarily work or are interested in. Future studies should try to replicate the current findings with other samples of students of different age levels and from different cultural backgrounds.

Despite these limitations, the present findings suggest that anti-bullying programs can discourage bullying behavior and encourage defending behavior among students by counteracting and deconstructing moral disengagement and fostering and strengthening moral emotions. Developing a sense of personal responsibility is crucial (e.g., Pozzoli \& Gini, 2012). To reduce moral disengagement among students, teachers and other school staff need to make students aware of and challenge moral disengagement mechanisms when they emerge among them as well as enhancing the moral atmosphere of the school and classroom, because school climate or moral atmosphere has been found to be negatively associated with the prevalence of bullying (e.g., Bonnet, Goossens, Willemen, \& Schuengel, 2009) and students' tendency to blame the victim of bullying (Gini, 2008). Among children in classrooms with more teacher emotional support (see Hamre et al., 2013), behavior problems are less common (McCormick, Capella, O’Connor, \& McClowry, 2013). According to a recently published qualitative study, a major theme in students' perceptions of teacher care was fostering emotional well-being, including providing comfort, connecting with students, and helping students feel valued (Jeffrey, Auger, \& Pepperell, 2013). In addition, prevention and interventions targeting the whole school class to decrease moral disengagement and bullying are important because bullies tend to have popular sociometric status (e.g., Farmer et al., 2010), which might indicate a widespread collective moral disengagement that normalizes, rationalizes, and justifies bullying (see Thornberg, 2015). Hence, moral disengagement at both individual and class levels has to be counteracted (see Pozzoli et al., 2012).

In particular, working with and enhancing students' moral emotions (empathy, sympathy for victims, guilt for bystander inaction, and guilt for harming others) appear to be crucial to minimize the moral disengagement effects on bullying and defending in bullying situations. From a moral philosophical point of view, emphasizing the need to foster moral emotions should not be confused with ethical subjectivism or "emotivism," arguing that no matter what moral judgments people make, they are expressing only their subjective feelings and nothing more (Rachels, 1999). On the contrary, moral emotions emerge from the experiences and conceptions of human welfare, justice, and rights, cognitively structured around considerations of the intrinsic effects that an individual's actions have on the well-being of other people, identified by Turiel (1983) and Nucci (2001) as the moral domain of human functioning and cognition. Thus, moral emotions are based on moral reasons. In accordance with that, induction has been suggested as a powerful method for parents and teachers to use in order to promote the development of moral emotions and 
cognitions (e.g., Hoffman, 2000; Turiel, 1983). Induction is about reasoning with children and making them aware of the effects of their actions on others. Hoffman (2000) argues that induction has two important functions: (a) calling attention to the victim's distress and making it salient to the child, thus "tapping into the child's empathic proclivity (using it as an ally) by activating any or all of his or her empathyarousing mechanisms and producing empathic distress" (p. 151), and (b) highlighting the role of the child's action in causing that distress, which creates conditions for feeling guilt.

Induction should be used when having serious conversations with bullies. Examples of induction would be to explain for the bullies how the victim is feeling because of their hurtful comments or ask questions such as, "How do you think she feels when you keep on excluding her from the group?" or "How would you feel if someone talks to you like that?" and then have a conversation to help the bully or the bullies notice and recognize the victim's feelings, especially his or her distress, by pointing out the effects of their behavior. Induction should also be used in conversations with witnessing children, who responded with negative bystander behaviors, such as assisting or reinforcing the bullies. Moreover, teachers could make efforts to prevent or tackle bullying through the curriculum (Cowie \& Sharp, 1994) by using films, drama, role-play, or literature about bullying and then initiating classroom or small group discussions powered by inductive questions and reasons.

Hence, in addition to addressing moral disengagement, bullying prevention needs to include strategies to promote students' moral emotions, and bullying interventions need to involve induction when addressing the bullies. Based on our findings, strengthening students' moral emotions should weaken the association between moral disengagement and bullying behavior as well as the negative association between moral disengagement and defending behavior.

\section{Note}

Robert Thornberg is professor and Tomas Jungert is associate professor in the Department of Behavioural Sciences and Learning, Linköping University. Tiziana Pozzoli is a research assistant and Gianluca Gini is an associate professor in the Department of Developmental and Social Psychology at the University of Padova. Address all correspondence to Robert Thornberg, Department of Behavioural Sciences and Learning, Linköping University, SE-58183 Linköping, Sweden; e-mail: robert.thornberg@liu.se.

\section{References}

Almedia, A., Correia, I., \& Marinho, S. (2010). Moral disengagement, normative beliefs of peer group, and attitudes regarding roles in bullying. Lournal of School Violence, 9, 23-36. doi:10.108o/ 15388220903185639.

Arsenio, W. F., \& Lemerise, E. A. (2004). Aggression and moral development: Integrating social information processing and moral domain models. Child Development, 75, 987-1002.

Bandura, A. (1986). Social foundations of thought and action: A social cognitive theory. Englewood Cliffs, NJ: Prentice-Hall.

Bandura, A. (1999). Moral disengagement in the perpetration of inhumanities. Personality and Social Psychologv Review, 3, 193-209. doi:10.1207/s15327957pspro303_3

Bandura, A. (2004). Selective exercise of moral agency. In T. A. Thorkildsen \& H. J. Walberg (Eds.), Nurturing morality (pp. 37-57). Boston: Kluwer Academic. 
Bandura, A., Barbaranelli, C., Caprara, G. V., \& Pastorelli, C. (1996). Mechanisms of moral disengagement in the exercise of moral agency. Iournal of Personality and Social Psychology, 71, 364374. doi:10.1037/0022-3514.71.2.364

Bandura, A., Caprara, G. V., Barbaranelli, C., \& Pastorelli, C. (2001). Sociocognitive self-regulatory mechanisms governing transgressive behavior. Lournal of Personality and Social Psychology, 8o, $125-135$.

Barchia, K., \& Bussey, K. (2011a). Individual and collective social cognitive influences on peer aggression: Exploring the contribution of aggression efficacy, moral disengagement, and collective efficacy. Aggressive Behavior, 35, 1-14. doi:10.1002/ab.20375

Barchia, K., \& Bussey, K. (2011b). Predictors of student defenders or peer aggression victims: Empathy and social cognitive factors. International Journal of Behavioral Development, 35, 289297. doi:10.1177/0165025410396746

Barhight, L. R., Hubbard, J. A., \& Hyde, C. T. (2013). Children's physiological and emotional reactions to witnessing bullying predict bystander intervention. Child Development, 84, 375390.

Baron, R. M., \& Kenny, D. A. (1986). The moderator-mediator variable distinction in social psychological research: Conceptual, strategic, and statistical considerations. Lournal of Personality and Social Psychology, 51, 1173-1182.

Barriga, A. Q., Sullivan-Cosetti, M., \& Gibbs, J. C. (2009). Moral cognitive correlates of empathy in juvenile delinquents. Criminal Behaviour and Mental Health, 19, 253-264. doi:10.1002/cbm.740

Bauman, S. (2008). The role of elementary school counselors in reducing bullying. Elementary School Journal, 108, 362-375. doi:10.1086/589467

Bierhoff, H-W. (2002). Prosocial behavior. Hove: Psychology Press.

Blair, R. J. R. (2001). Neurocognitive models of aggression, the antisocial personality disorders, and psychopathy. Lournal of Neurology, Neorosurgerv \& Psychiatry, 71, 727-731. doi:10.1136/ jnnp.71.6.727

Bonnet, M., Goossens, F. A., Willemen, A. M., \& Schuengel, C. (2009). Peer victimization in Dutch school classes of four- to five-year-olds: Contributing factors at the school level. Elementary School Journal, 110, 163-177. doi:10.1086/605769

Caravita, S. C. S., Di Blasio, P., \& Salmivalli, C. (2009). Unique and interactive effects of empathy and social status on involvement in bullying. Social Development $, 18,140-163$. doi:10.1111/j.1467-9507.2008.00465.x

Caravita, S. C. S., Di Blasio, P., \& Salmivalli, C. (2010). Early adolescents' participation in bullying: Is ToM involved. Lournal of Early Adolescence, 30, 138-170. doi:10.1177/0272431609342983

Caravita, S. C. S., Gini, G., \& Pozzoli, T. (2012). Main and moderate effects of moral cognition and status on bullying and defending. Agoressive Behavior, 38, 456-468. doi:10.1002/ ab. 21447

Caravita, S. C., Miragoli, S., \& Di Blasio, P. (2009). "Why should I behave in this way?" Rule discrimination within the school context related to children's bullying. In L. R. Elling (Ed.), Social development (pp. 269-290). New York: Nova Science.

Carlo, G., Mestre, M. V., Samper, P., Tur, A., \& Armenta, B. E. (2010). Feelings of cognitions? Moral cognitions and emotions as longitudinal predictors of prosocial and aggressive behaviors. $\underline{\text { Per- }}$ sonality and Individual Differences, 48, 872-877. doi:10.1016/j.paid.2010.02.010

Cornell, D. G., \& Bandyopadhyay, S. (2010). The assessment of bullying. In S. R. Jimerson, S. M. Swearer, \& D. L. Espelage (Eds.), Handbook of bullying in schools: An international perspective (pp. 265-276). New York: Routledge.

Correia, I., \& Dalbert, C. (2008). School bullying: Belief in a personal just world of bullies, victims, and defenders. European Psychologist, 13, 248-254. doi:10.1027/1016-9040.13.4.248

Cowie, H., \& Sharp, S. (1994). Tackling bullying through the curriculum. In P. K. Smith \& S. Sharp (Eds.), School bullying: Insights and perspectives (pp. 84-107). London: Routledge.

Eisenberg, N. (2000). Emotion, regulation, and moral development. Annual Review of Psychology, 51, 665-697. doi:10.1146/annurev.psych.51.1.665

Eisenberg, N., Eggum, N. D., \& Di Giunta, L. (2010). Empathy-related related responding: Associations with prosocial behavior, aggression, and intergroup relations. Social Issues and Policy Review, 4, 143-180. doi:10.1111/j.1751-2409.2010.01020.x 
Eisenberg, N., Spinrad, T. L., \& Sadovsky, A. (2006). Empathy-related responding in children. In M. Killen \& J. G. Smetana (Eds.), Handbook of moral development (pp. 517-549). Mahwah, NJ: Erlbaum.

Emler, N., \& Tarry, H. (2007). Clutching at straws: Is it time to abandon the moral judgment deficit explanation for delinquency? British Journal of Developmental Psychology, 25, 191-195.

Farmer, T. W., Petrin, R. A., Robertson, D. L., Fraser, M. W., Hall, C. M., Day, S. H., \& Dadisman, K. (2010). Peer relations of bullies, bully-victims, and victims: The two social worlds of bullying in second-grade classrooms. Elementary School Journal, 110, 364-392. doi:10.1086/648983

Frazier, P. A., Tix, A. P., \& Barron, K. E. (2004). Testing moderator and mediator effects in counseling psychology research. Lournal of Counseling Psychology, 51, 115-134.

Gasser, L., \& Keller, M. (2009). Are the competent the morally good? Perspective taking and moral motivation of children involved in bullying. Social Development, 18, 798-816.

Gibbs, J. C. (2010). Moral development and reality: Beyond the theories of Kohlberg and Hoffman. Boston: Allyn \& Bacon.

Gini, G. (2006). Social cognition and moral cognition in bullying: What's wrong? Aggressive Behavior, 32, 528-539. doi:10.1002/ab.20153

Gini, G. (2008). Italian elementary and middle school students' blaming the victim of bullying and perception of school moral atmosphere. Elementary School Journal, 108, 335-354. doi:10.1086/ 528975

Gini, G., Albiero, P., Benelli, B., \& Altoè, G. (2007). Does empathy predict adolescents' bullying and defending behavior? Aggressive Behavior, 33, 467-476. doi:10.1002/ab.20204

Gini, G., Pozzoli, T., \& Hauser, M. (2011). Bullies have enhanced moral competence to judge relative to victims, but lack moral compassion. Personality and Individual Differences, 50, 603608. doi:10.1016/j.paid.2010.12.002

Gini, G., Pozzoli, T., \& Hymel, S. (2014). Moral disengagement among children and youth: A meta-analytic review of links to aggressive behavior. Agoressive Behavior, 40, 56-68. doi: 10.1002/ab.21502

Gray, K., \& Wegner, D. M. (2011). Dimensions of moral emotions. Emotion Review, 3, 258-260.

Haidt, J. (2003). The moral emotions. In R. J. Davidson, K. R. Scherer, \& H. H. Goldsmith (Eds.), Handbook of affective sciences (pp. 852-870). New York: Oxford University Press.

Hamre, B. K., Pianta, R. C., Downer, J. T., DeCoster, J., Mashburn, A. J., Jones, S. M., Brown, J. L., Cappella, E., Atkins, M., Rivers, S. E., Brackett, M. A., \& Hamagami, A. (2013). Teaching through interactions: Testing a developmental framework of teacher effectiveness in over 4,000 classrooms. Elementary School Journal, 113, 461-487. doi:10.1086/669616

Hoffman, M. L. (2000). Empathy and moral development. Cambridge: Cambridge University Press. Hyde, L. W., Shaw, D. S., \& Moilanen, K. L. (2010). Developmental precursors of moral disengagement and the role of moral disengagement in the development of antisocial behavior. Iournal of Abnormal Child Psychology, 38, 197-209.

Hymel, S., Rocke-Henderson, N., \& Bonanno, R. A. (2005). Moral disengagement: A framework for understanding bullying among adolescents. Journal of Social Sciences, 8, 1-11.

Hymel, S., Schonert-Reichl, K. A., Bonanno, R. A., Vaillancourt, T., \& Rocke Henderson, N. (2010). Bullying and morality. In S. R. Jimerson, S. M. Swearer, \& D. L. Espelage (Eds.), Handbook of bullying in schools: An international perspective (pp. 101-118). New York: Routledge.

Jeffrey, A. J., Auger, R. W., \& Pepperell, J. L. (2013). “If we're ever in trouble they're always there": A qualitative study of teacher-student caring. Elementary School Journal, 114, 100-117. doi: $10.1086 / 671062$

Jolliffe, D., \& Farrington, D. P. (2006). Development and validation of the Basic Empathy Scale. Lournal of Adolescence, 29, 589-611. doi:10.1016/j.adolescence.2005.08.010

Jöreskog, K., \& Sörbom, D. (1993). LISREL 8: Structural modeling with the SIMPLIS command lööanguage. Chicago: Scientific Software International.

Kohlberg, L. (1976). Moral stages and moralization: The cognitive-developmental approach. In T. Lickona (Ed.), Moral development and behavior: Theory, research, and social issues (pp. 31-53). New York: Holt, Rinehart \& Winston.

Kohlberg, L. (1984). Essays on moral development: Vol. 2. The psychology of moral development: Moral stages and the idea of justice. San Francisco: Harper \& Row. 
Lotze, G. M., \& Ravindran, N., \& Myers, B. J. (2010). Moral emotions, emotion self-regulation, callous-unemotional traits, and problem behavior in children of incarcerated mothers. Lournal of Child and Family Studies, 19, 702-713. doi:10.1007/s10826-010-9358-7

MacEvoy, J. P., \& Leff, S. S. (2012). Children's sympathy for peers who are targets of peer aggression. Journal of Child Psychology, 40, 1137-1148. doi:10.1007/s10802-012-9636-5

Malti, T., \& Krettenauer, T. (2013). The relation of moral emotion attributions to prosocial and antisocial behavior: A meta-analysis. Child Development, 84, 397-412. doi:10.1111/j.14678624.2012.01851.X

Malti, T., \& Latzko, B. (2010). Children's moral emotions and moral cognition: Towards and integrative perspective. New Directions for Child and Adolescent Development, 2010, 129, 1-10. doi:10.1002/cd.272

McCormick, M. P., Cappella, E., O’Connor, E. E., \& McClowry, S. G. (2013). Parent involvement, emotional support, and behavior problems. Elementary School Journal, 114, 277-300. doi: $10.1086 / 673200$

Menesini, E., Esla, M., Smith, P. K., Genta, M. L., Giannetti, E., Fonzi, A., et al. (1997). A crossnational comparison of children's attitudes towards bully/victim problems in school. Aggressive Behavior, 29, 1-13.

Menesini, E., Sanchez, V., Fonzi, A., Ortega, R., Costabile, A., \& Lo Feudo, G. (2003). Moral emotions and bullying: A cross-national comparison of differences between bullies, victims and outsiders. Aggressive Behavior, 29, 515-530. doi:10.1002/ab.10060

Nucci, L. P. (2001). Education in the moral domain. Cambridge: Cambridge University Press.

Obermann, M-L. (2011a). Moral disengagement in self-reported and peer-nominated school bullying. Aggressive Behavior, 37, 133-144. doi:10.1002/ab.20378

Obermann, M-L. (2011b). Moral disengagement among bystanders to school bullying. Iournal of School Violence, 10, 239-257. doi:10.1080/15388220.2011.578276

Olthof, T. (2012). Anticipated feelings of guilt and shame as predictors of early adolescents' antisocial and prosocial interpersonal behavior. European Journal of Developmental Psychology, 9 , 371-388. doi:10.1080/17405629.2012.680300

Paciello, M., Fida, R., Tramontano, C., Lupinetti, C., \& Caprara, G. V. (2008). Stability and change in moral disengagement and its impact on aggression and violence in late adolescence. Child Development, 79, 1288-1309. doi:10.1111/j.1467-8624.2008.01189.x

Pelton, J., Gound, M., Forehand, R., \& Brody, G. (2004). The Moral Disengagement Scale: Extension with an American minority sample. Lournal of Psychopathology and Behavioral Assessment, 26, 31-39. doi:10.1023/B:JOBA.0000007454-34707.a5

Perren, S., \& Gutzwiller-Helfenfinger, E. (2012). Cyberbullying and traditional bullying in adolescence: Differential roles of moral disengagement, moral emotions, and moral values. European Iournal of Developmental Psychology, 9, 195-209. doi:10.1080/17405629.2011.643168

Perren, S., Gutzwiller-Helfenfinger, E., Malti, T., \& Hymel, S. (2012). Moral reasoning and emotion attributions of adolescent bullies, victims, and bully-victims. British Journal of Developmental Psvchologv, 30, 511-530. doi:10.1111/j.2044-835X.2011.02059.X

Piaget, J. (1932). The moral judgment of the child. New York: Free Press.

Pornari, C. D., \& Wood, J. (2010). Peer and cyber aggression in secondary school students: The role of moral disengagement, hostile attribution bias, and outcome expectancies. Aggressive Behavior, 36, 81-94. doi:10.1002/ab.20336

Pozzoli, T., \& Gini, G. (2010). Active defending and passive bystanding behavior in bullying: The role of personal characteristics and perceived peer pressure. Lournal of Abnormal Child Psvchology, 38(6), 815-827. doi:10.1007/s10802-010-9399-9

Pozzoli, T., \& Gini, G. (2012). Why do bystanders of bullying help or not? A multidimensional model. Lournal of Early Adolescence, 33, 315-340. doi:10.1177/0272431612440172

Pozzoli, T., Gini, G., \& Vieno, A. (2012). Individual and class moral disengagement in bullying among elementary school children. Aggressive Behavior, 38, 378-388. doi:10.1002/ab.21442

Rachels, J. (1999). The elements of moral philosophy (3rd ed.). Boston: McGraw-Hill.

Roos, S., Salmivalli, C., \& Hodges, V. E. (2011). Person $\times$ context effects on anticipated moral emotions following aggression. Social Development, 20, 685-702. doi:10.1111/j.14679507.2011.00603.x 
Silfver, M., \& Helkama, K. (2007). Empathy, guilt, and gender: A comparison of two measures of guilt. Scandinavian Journal of Psychology, 48, 239-246. doi:10.1111/j.1467-9450.2007.00578.x

Smith, P. K., \& Sharp, S. (1994). The problem of school bullying. In P. K. Smith \& S. Sharp (Eds.), School bullying: Insights and perspectives (pp. 1-19). London: Routledge.

Stavrinides, P., Georgiou, S., \& Theofanous, V. (2010). Bullying and empathy: A short-term longitudinal investigation. Educational Psvchologv, 30, 793-802. doi:10.1080/01443410.2010.506004 Swedish National Agency for Education. (2013). Attityder till skolan 2012 [Attitudes toward school 2012]. Report 390. Stockholm: Skolverket.

Tisak, M. S., Tisak, J., \& Goldstein, S. E. (2006). Aggression, delinquency, and morality: A socialcognitive perspective. In M. Killen \& J. G. Smetana (Eds.), Handbook of moral development (pp. 611-629). Mahwah, NJ: Erlbaum.

Thornberg, R. (2010). A study of children's conceptions of school rules by investigating their judgments of transgressions in the absence of rules. Educational Psychology, 30, 583-603. doi: 10.1080/01443410.2010.492348

Thornberg, R. (2015). School bullying as a collective action: Stigma processes and identity struggling. Children \& Society, 29, 310-320. doi:10.1111/chso.12058

Thornberg, R., Birberg Thornberg, U., Alamaa, R., \& Daud, N. (in press). Children's conceptions of bullying and repeated conventional transgressions: Moral, conventional, structuring, and personal-choice reasoning. Educational Psychology. doi:10.1080/01443410.2014.915929

Thornberg, R., \& Jungert, T. (2013). Bystander behavior in bullying situations: Basic moral sensitivity, moral disengagement and defender self-efficacy. Lournal of Adolescence, 36, 475-483. doi:10.1016/j.adolescence.2013.02.003

Thornberg, R., \& Jungert, T. (2014). School bullying and the mechanisms of moral disengagement. Agrressive Behavior, 40, 99-108. doi:10.1002/ab.21509.

Turiel, E. (1983). The development of social knowledge. Cambridge: Cambridge University Press. 